\title{
DA INICIATIVA DAS PROVAS E DOS PODERES DO JUIZ DE DIREITO ROMANO E NA ATUALIDADE *
}

\author{
ALOÍSIO SURGIK**
}

\section{INTRODUÇÃO}

Tema dos mais palpitantes na atualidade, entre os estudiosos do Direito Processual Civil, é o de estabelecer em que medida o juiz deve tomar a iniciativa das provas.

Segundo o princípio dispositivo, o juiz deve julgar conforme o alegado e provado pelas partes, enquanto o princípio inquisitório afirma a livre iniciativa do juiz.

Assim, o princípio da disponibilidade ou princípio disposivo é aquele segundo o qual o processo é dominado pela vontade das partes, que o podem eficazmente orientar nos sentidos em direção aos resultados - que bem lhes pareçam.

A admissão deste princípio está necessariamente em estreita ligação com uma visão ou concepção privatística do processo.

Ao princípio dispositivo opõe-se o princípio da inquisitoriedade ou princípio inquisitório, segundo o qual o processo é dominado pela vontade daquele que o deve julgar, e que recebe da ordem jurídica poderes para o conduzir e orientar para uma decisão justa.

O princípio inquisitório liga-se logicamente a uma visão ou concepção publicística do processo civil ${ }^{1}$.

No processo penal, exatamente porque não se fala em disponibilidade de direito, o princípio dispositivo fica em segundo plano. No processo civil, ao contrário, sempre que se trata de

* Trabalho sustentado durante o II Coloquio ftalo-Brasileiro de Direito Romano, realizado na Faculdade de Direito da UFRJ, de 17 a 19 de agosto de 1981 .

** Professor de Direito Romano das Universidades Federal e Católíca do Paraná. Doutorando em Direito pela USP. 
demanda acerca de interesses patrimoniais entre capazes, vige o princípio dispositivo.

Todavia, no próprio processo civil, hoje instrumento do Estado, acentua-se a tendência de ampliar os poderes do juiz, em dentrimento do princípio dispositivo. Assim, inclusive nos processos que versam sobre interesses patrimoniais entre capazes e em que deve prevalecer o princípio dispositivo, verifica-se uma crescente tendência no sentido de reprimir o princípio dispositivo e ampliar o princípio inquisitório.

Até mesmo no direito privado em geral, como diz o Prof. Washington de Barros Monteiro, observa-se, presentemente, acentuada tendência publicística, isto é, interferência do direito público em relações jurídicas até agora reservadas exclusivamente ao primeiro, como acontece com a legislação protetora do inquilinato e da família. Aliás, todo o direito de família caminha para o direito público" 2 .

Explica Alberto Moniz da Rocha Barros: "O progressivo aumento do poder do Estado tem repercussões cada vez mais numerosas e intensas no que são relações entre particulares, pertinentes ao campo do Direito Privado" 3 .

Segundo o mesmo autor, no Direito Processual - Civil e Penal - o interesse público arrebata terreno à soberania do indivíduo ${ }^{4}$.

Cumpre-nos esclarecer que estas distinções e denominações - princípio dispositivo, princípio inquisitório - não são romanas. Todavia, tendo em vista a atual absorção da prática judiciária pelo Estado, o presente trabalho tem por objetivo examinar à luz da evolução histórica, em linhas gerais, algumas causas que determinaram a crescente publicização do processo civil, particularmente no tocante às provas e à margem de poderes atribuídos ao juiz.

\section{A VONTADE DAS PARTES NO PROCESSO ROMANO CLÁSSICO}

No período clássico do direito romano, chamado "ordo iudiciorum privatorum", a tarefa do juiz, que era escolhido livremente pelas partes, limitava-se a pronunciar "in iudicio" a sentença, dentro dos estritos limites propostos ${ }^{5}$.

A fase "in iudicio" era despida de formalismo, podendo 
as partes e o juiz manifestar-se em quaisquer termos. As partes deduziam as suas razões orais (causae coniectio), passando, então, à fase da produção das provas, em que todas eram admitidas, especialmente as testemunhas, desempenhando estas um papel essencial em uma época em que os atos escritos eram raros ${ }^{6}$.

A ampla disponibilidade das partes no processo romano clássico, em que ainda não eixstia a personificação do Estado absorvendo as atividades judiciárias, assim é vista por Emilio Costa: "Codesta Libertà assoluta lasciata al giudice, circa i mezzi coi quali egli può formare il proprio convincimento e l'aprezzamento che può dare alle risultanze di ciascuno di questi, constituisce una naturale emergenza del carattere del suo officio arbitrale; che egli esercita essenzialmente sulla base di un contrato delle parti, e quale fiduciario di entrambe. Tale carattere non consente limitazioni e discipline nel valore degli strumenti probatori, quali intervengono invece nal periodo sucessivo, allorchè il giudice magistrato assume a nome dello Stato ed in rappresentanza di questo l'ufficio di attuare la giustizia" '

A própria "litiscontestatio", que marca o momento culminante do processo romano clássico, em que se encerra a fase procesual "in iure" com a escolha do juíz pelas partes (accipere iudicium) ${ }^{8}$, é um verdadeiro contrato, embora alguns autores chamem de contrato judiciário ${ }^{9}$, em atenção à expressão "iudicio contrahi" de Pompônio ${ }^{10}$.

Durante o período clássico, que compreende aproximadamente quatro séculos consecutivos, desde meados do século II a. C. até a queda da dinastia dos Severos (ano 235), o direito romano, embora com peculiaridades diversas nas diversas fases deste período, apresenta-se com todas as características próprias de um direito jurisprudencial, na mais eloqüente expressão do que hoje chamamos Direito Privado.

No modelo jurisprudencial romano, o jurista é o verdadeiro depositário e responsável pela elaboração do direito. Não que se lhe tenha atribuido esta função oficialmente, mas porque socialmente é quem se encontra em condições de exercer tal atividade criadora; as normas procedentes das fontes "oficiais", primeiramente leis e plebiscitos, depois "senatusconsultus" e constituições imperiais, têm caráter secundário, pois em princípio, como diz Alejandrino Fernandes Barreiro ${ }^{11}$, os órgãos investidos do poder político permaneceu alheios a uma ordem essencialmente interindividual como é, para os romanos, o direi- 
to privado; a intervenção "oficial" no campo do direito privado não é, portanto, de caráter "legislativo", porém judicial e processual, e o processo pressupõe as relações interindividuais, que se limita a tutelar.

Nota peculiar a todo direito de juristas é a estreita relação entre direito e processo, a ponto de um ordenamento jurídico deste tipo se apresentar, não como um conjunto de direitos subjetivos, porém na forma de um sistema de ações, ou, em todo caso, conforme uma concepção jurídica dinâmica em relação com o processo ${ }^{12}$. É portanto coerente com o caráter jurisprudencial do direito romano clássico que os juristas atuem especialmente através do processo para introduzir inovações jurídicas.

Salienta ainda Alejandrino Fernandes Barreiro ${ }^{13}$ que a absorção da autoridade pelo poder, que em Roma se inicia com Augusto, implica também a abolição da "libertas" e, largamentè, a destruição das condições de existência e desenvolvimento de um direito de juristas, e a concentração no poder público da produção do direito, através de disposições legais.

Percebe-se que, no decurso da História, à medida em que a atividade jurisprudencial se concentra no poder público, desenvolve-se também, e ganha certa predominância, a chamada prova legal.

No que diz respeito à faculadade do juiz de interrogar as partes pessoalmente sobre qualquer ponto da controvérsia, cumpre lembrar que tal prerrogativa foi reconhecida pelo direito romano, pelo direito dos povos bárbaros e pelo direito comum ${ }^{14}$, devendo advertir-se quanto ao direito romano, que não se deve confundir o interrogatório propriamente dito com as "actiones interrogatoriae" e as "interrogationes in iure", próprias do procedimento formulário ${ }^{15}$.

Com o fortalecimento do poder imperial romano, os poderes do juiz parece que se fortalecem também. Contudo, este fortalecimento é meramente ilusório, como veremos a seguir.

\section{O ILUSÓRIO FORTALECIMENTO DOS PODERES DO JUIZ NO DIREITO ROMANO PÓS-CLÁSSICO}

Enquanto, o juiz era, no direito romano clássico, uma pessoa do povo, eleito entre o povo, de comum acordo entre as partes, sendo provável que já na época das "Legis Actiones" 
havia um "álbum" de juízes, e que, quando as partes não tivessem providenciado outro nome, o magistrado invitava as frartes a escolherem um dos que integrassem o "álbum", procedendose a sorteio em caso de desacordo ${ }^{16}$, no período pós-clássico, época da "cognito extra-ordinária", o juiz é um magistrado. Atua representando o poder imperial, agindo, portanto, no interesse do mesmo. Não pode, pois, na valoração das provas aduzidas relas partes, proceder com aquela mesma liberdade com que procedia no período precedente, em que intervinha com caráter arbitral.

Eis, na abalizada palavra de Emilio Costa, a atuação judicial na "extraordinária cognitio": "Il giudice magistrato, che nel periodo di cui discorriamo ha per ufficio di attuare, in rappresentanza dello Stato, la giustizia fra i litiganti, non può procedere nella valutazione degli elementi di prova addoti da essi, od emergenti altrimenti in guisa indiretta da datti obbjettivi, con quella medesima libertà colla quale procedeva nel periodo precedente il giudice, che interveva a conoscere della controversia con carattere arbitrale. Egli è tenuto bensi ad attenersi nella valutazione dei detti elementi a certe norme e discipline legalmente stabilite: che fissano per essi un valore diverso" ${ }^{17}$.

Acentua-se a preferência pelos documentos escritos, com o progressivo declínio da prova testemunhal, a ponto de se estabelecer como princípio geral a ineficácia do testemunho contra a prova escrita ${ }^{18}$.

Várias constituições emanadas no período que vai entre Constantino e Justiniano estabelecem para a prova testemunhal uma grande multiplicidade de normas, fixando, antes de mais nada, a ineficácia de uma única testemunha ${ }^{19}$, por mais fidedigna que se mostre; determinando o grau de credibilidade de cada testemunha, em razão da respectiva condição social ${ }^{20}$; não atribuindo qualquer valor ao testemunho dos hereges e dos judeus nas causas propostas contra ortodoxos ${ }^{21}$, estabelecendo a obrigatoriedade geral de prestar testemunho a quem fosse intimado ${ }^{22}$; usando o juramento como reforço ao valor testemunhal ${ }^{23}$ e a tortura contra a testemunha cuja veracidade parecesse suspeita ${ }^{24}$, podendo tal medida ser aplicada pelo próprio juiz, na falta de "administratores" ${ }^{25}$.

Há profunda antítese entre a acepção imperial e a clássica no que diz respeito à liberdade de disposição das partes no processo, porquanto passa a viger no sistema imperial o prin- 
cípio inquisitório, conforme se dessume claramente das fontes ${ }^{26}$, embora haja quem sustente 0 contrário, com base numa constituição de Diocleciano ${ }^{27}$.

Ugo Ziletti ${ }^{28}$ assim se expressa: "Cosi, solo per esclusione si ricava l'ambito del potere di disposizione delle "intentiones", expressamente limitato alla fase preliminare alla chiamata in giudzio: ciò significa, puramente e semplicemente, che il privato è libero di disporre della tutela giurisdizionale delle sue ragioni materiali fino al determinarse della litispenza, è libero cioè di scegliere o meno la via del processo. Una volta pervenuto alla chiamata in giudzio, la possibilità di una sentenza di merito non può essere eliminata o allontanata soltanto per effetto di volontaria inattività, cioè di un comportamento processuale che per Giustiniano non solo non ha valore di dichiarazione di rinuncia, ma piu in generale non ha efeetto necessário sulla domanda".

Por mais que se queira vislumbrar o princípio dispositivo no direito justinianeu, faz-se nítida a predominância do princípio inquisitório.

Tal tendência em todo o direito romano pós-clássico e principalmente no direito justinianeu se explica em razão do fortalecimento do poder imperial e, no caso específico de Justiniano, pelo fato de o mesmo ter procurado por todos os meios centralizar todos os poderes em sua pessoa.

Aparentemente, o juiz ganha mais poderes, porquanto dispõe de maior margem de inquisitoriedade. Porém, na realidade, tais poderes são meramente ilusórios, eis que ele se torna apenas uma peça da complicada máquina burocrática imperial, e, o que é pior, seus movimentos ficam tolhidos nas malhas do normativismo, sob a imposição da chamada prova legal.

\section{O PRINCÍPIO DA DISPONIBILIDADE NAS FONTES PÓS-JUSTINIANÉIAS}

No Código Visigótico, ou "Liber ludicum", que os espanhóis chamam de "Fuero Juzgo" promulgado pelo rei Rescesvindo, depois do Concílio VIII de Toledo, e que recebeu forte infuência eclesiástica por influxo do Código Teodosiano ${ }^{20}$, ressalvava a praxe do juramento por ordem do juiz, parece que em geral predominava o princípio dispositivo, devendo, o juiz, limitar-se às provas produzidas pelas partes: “En 
los pleytos que el juiez oye, cada una de las partes deve dar sus pesquisas é sus pruevas, y el juez deve catar qual prueva mejor. E si por las pruevas non pudiere saber la verdad, estonze deve mandar el juez á aquel de quien se querellavan, que se salve por sua sacramento, que aquella cosa quel demandan, non la ovo, ni la a, ni save ende nada, ni lo cree, ni que non fizo aquello quel dizen. E pues que jurar aquel quer demandó tuerto, peche V. sueldos" (Fuero Juzgo, 2, 2, 6) ${ }^{30}$.

Já no antigo livro "Flores de las Leyes", precioso compêndio de direito processual, sem dúvida uma das obras mais importantes da literatura jurídica medieval, e que representa uma das manifestações mais nítidas e diretas do renascimento do direito romano, na Península, podendo dizer-se que é o primeiro livro em que se revela já florescente a cultura do direito justinianeu $" 1$, por isto mesmo, pela influência justinanéia, avulta a proeminência do princípio inquisitório. Basta citarmos a passagem que segue: "... aquelhes que nossas justiças teuerê ena uilla por nos, e os que no podere saber por prouas que o sabyã por pesquisa e per quantias partes mayor uerdade pode saber e segundo o que achare que no feyto que atal pea lhy den morte se a merecer ou aquello que entender que deue receber segundo a culpa en que o achare..." (FI. 32 r. ${ }^{32}$.

Todavia, no livro "Las Siete Partidas del Sabio Don Afonso", que alcançou enorme aceitação em Portugal, a ponto de constituir importante fonte da primeira grande codificação portuguesa (as "Ordenações Afonsinas") ${ }^{33}$, o juiz não pode tomar a iniciativa das provas, porquanto as perguntas e resposta em juízo são feitas pelas próprias partes, podendo também o juiz perguntar, porém no estrito limite da demanda: "Començamiento tomam los pleytos por las demandas, e por las resquestas que fazen las partes en juyzio" 34 ... pergunta, es cosa de que nace grand pro. Ca por ella puede el judgador saber mas en cierto la verdade delos pleytos, e delos fechos dubdosos, que vienen ante el. E puede la fazer el juez, fasta que de el juyzio: e aun la vna ala otra, ante el judgador. $\mathrm{E}$ due ser de tal natura, que pertenezca al fecho, o a la cosa sobre que es la contienda" ${ }^{53}$.

Esta orientação foi assimilada pelo gênio lusitano e reflete-se nas Ordenações Afonsinas: "Todo julguador, e juiz boo deve ser avizado, que sempre julgue segundo que achar no feito aleguado, e provado por as partes, assy Author, como Reo, tendo sempre maneira em como sua Sentença seja sempre conforme a sustancia (petiçam) fundando-se nas provas dadas por as 
partees, como dito he; e não deve salvo em quanto ella fosse formada por as alegaçoens, e provas, que se o juiz achasse por o feito provada a Auçam do Author, sem outra prova feita por parte do Reo, perque a emtenção do Autor fosse anichelada em todo, em tal caso deverá condenar o Reo, non embargante, que per outra quisa fóra do processo elle soubesse a verdade ser em contrairo; salvo se elle houvesse essa emformação fóra do processo como juiz, sendo em seu Tribunal, ou em algum Auto judicial, ca em tal caso poderá julgar segundo sua Conciencia formada por o que vio como juiz, sendo em juizo pubrico, como dito he" ${ }^{36}$.

Este mesmo critério passou para as Ordenações Manuelinas: "Todo julguador ... dee a sentença definitiva, segundo o que achar prouado de huã parte e da outra, ainda que lhe a consciencia dite o contrairo, e ele saiba a verdade seer em contrairo, do que no feito for prouado, porque soomente ao Principe, que não reconhece superior, he dado outorguado por Dereito, que jugue segundo sua consciência non curando d'aleguações, ou prouas em contrairo feitas polas partes. $E$ ainda sera auisado, que sempre dee a sentença conforme ao libelo conuen a saber, condenado, ou absoluendo, em todo ou em parte, segundo o que achar prouado polo feito, como dito he":i7.

Nas Ordenações Filipinas, igualmente se tolhe a iniciativa do juiz, devendo ele julgar "segundo o que achar provado de uma e de outra parte, ainda que lhe a consciência dite outra coisa, e ele saiba a verdade ser em contrário do que no feito for provado" 38 .

No direito pátrio, também até há pouco tempo, prevaleceu esta mesma orientação. Em alguns casos, todavia, a regra de que só às partes cumpria produzir a prova sofria exceções. Assim, quando as partes já tivessem produzido suas provas e os autos se achassem conclusos para a sentença, o juiz podia abrir a conclusão, porém "para melhor se inteirar da verdade, mandando proceder a qualquer diligência que se the afigure apropriada àquele fim. $E$ a razão é porque, como diz Valasco (Consult. 43, n. 14), em citação feita por Moacyr Amaral Santos ${ }^{39}$, "judicem hoc facere posse, quia ipse nunquam concluditur in causa, $1.3, \S 1 .^{\circ}, \mathrm{fr}$. de test. et judex de propositis in judicio potest etiam nemine petente interrogare partes, ad eruendam veritatem, non solum ante conclusionem in causa, quod non est dubium, sed etiam post".

Tal posição, inquestionavelmente se mostra como reflexo 
da remota porém atuante influência justinianéia, tendente ao princípio inquisitório ${ }^{40}$, pelas razões anteriormente expostas.

Entretanto, vingava no processo brasileiro o sistema fundado no princípio de disposição das partes, isto é, o de atribuir às partes a iniciativa da escolha e da produção das provas, sem que com isso se deixasse de conceder ao juiz o poder de, "ex officio", determinar diligências que viessem esclarecer pontos obscuros deixados por aquelas, de modo a melhor formar a sua convicção sobre os fatos controvertidos. Assim, a iniciativa judicial era meramente supletiva da iniciativa dos litigantes. Apenas quando da prova por estes produzida resultasse para o juiz a impressão de que era possível ser esclarecida, ou mesmo aperfeiçoada no sentido de melhor se inteirar da verdade e mais segura se formar a sua convicção, the era permitido converter o julgamento em diligência para se proceder a novas everiguações ${ }^{41}$.

Cumpre agora considerarmos as tendências que orientaram em sentido diverso o Código de Processo Civil Brasileiro de 1939.

\section{AS TENDÊNCIAS DO CÓDIGO DE PROCESSO CIVIL BRASILEIRO DE 1939}

Disse Gabriel de Rezende Filho: "O Estado moderno, esporeado pelas necessidades que se multiplicam, invade o campo da atividade individual, dilata os limites de sua jurisdição, amplia a zona de sua influência, restringindo, por via de conseqüências, a esfera das liberdades individuais" 42. E George Ripert: "As transformações da vida econômica impõem as modificações técnicas do direito. Mas não podem explicar o abandono dos princípios" ${ }^{43}$.

Ainda Gabriel Rezende Filho, referindo-se ao Código de Processo Civil de 1939, foi categórico: "O moderno Código de Processo Civil Brasileiro afastou-se deliberadamente dos princípios privatísticos do nosso velho processo, consagrando, de revés, o princípio publicístico, que se pode resumir nestas palavras: concentração processual rigorosa, oralidade adequada e autoridade do juiz" 44 .

"Já no primeiro quartel deste século - esclarece Moacyr Amaral Santos ${ }^{45}$, se manifestavam no país movimentos favoráveis à adoção da doutrina em que se assentavam as reformas 
processuais então havidas recentemente na Áustria, na Alemanha e Hungria. Enquanto Espínola redigia o Código de Processo do Estado da Bahia, Gusmão propagava, da catédra da Faculdade de Direito de São Paulo, a nova doutrina, aquele e este respirando ensinamentos de autores germanos e italianos principalmente ${ }^{46}$.

Giuseppe Chiovenda foi o grande paladino dos princípios publicísticos do processo. Mostrando que o processo antigo se fundava numa concepção patrimonial da jurisdição vinda do regime feudal, advogava, com tenaz pugnacidade, uma reforma com a qual queria "assecurare al giudice una posizione che lo renda partecipe attivo nel rapporto processuale, e munirlo dell' autorità necessaria per esercitar la sua funzione" ${ }^{47}$.

A propósito da reforma processual italiana, não faltou quem a criticasse. Assim, Antonio Segni e Sergio Costa, "in" "Novissimo Digesto Italiano", observam: "In Italia, all'atto della riforma processuale, effetuata nel Regno di Sardegna, la questione della forma, scritta od orale, del procedimento, fu posta: ma impostata male, fu risolta peggio, perchè si credette di resolverla dando la preferenza ad un procedimento misto, ossia quello in cui gli atti precipui della causa, quelli che più peculiarmente determinano il fatto e le prove, si fanno 'per iscritto e poi all' udienza si riferisce la causa e si disputano oralmente e si dibattono "hinc inde" le ragioni' (Vedi Chiovenda, Principi di diritto processuale civile, 3. ${ }^{\text {a }}$ ediz. Napoli, 1933, p. 10-11)" 48.

O código de Processo Civil brasileiro de 1939, adotando como padrão o Código Austríaco, cujo característico fundamental é o aumento dos poderes do juiz ${ }^{49}$, no dizer de José Monteiro de Castro ${ }^{50}$, deixou de se adaptar às nossas condições de vida, às nossas possibilidades, tomadas estas no sentido de uma cultura essencial pela falta de preparação do elemento humano que o aplicasse com exatidão.

À implantação do Estado autoritário, em 1937, como era fatal, seguiu-se o reforço do poder do juiz, como órgão do Estado - e eis o juiz autoritário. O princípio dispositivo, tradicional no processo, é substituído pelo princípio inquisitório, refletindo, assim, na justiça, as opiniões ou mutações políticas e espirituais dos governantes da época ${ }^{51}$. "Ora, sendo o processo um assunto público, uma demonstração do poder governamental em favor da comunidade, e não uma explicação entre as partes, é impossível entregá-lo ao seu arbítrio: em um Estado autoritá- 
rio, este dominará, necessariamente, a instituição do direito civil. Esta direção predomina tanto na direção do processo, quanto no seu conteúdo" 52 .

Observa Giuseppe Maranini que "uma vez instaurado o processo, e enquanto ele tem vida, o Estado, na pessoa do juiz, intervém autoritariamente para discipliná-lo e também para impulcioná-lo, pois que muitas vezes ao impulso da parte se substitui, sob importantes aspectos, o impulso oficial (seja por exemplo, nos casos de notificações de ofício, dos provimentos preparatórios e de instrução, ou seja, o que é mais freqüente, através dos amplos poderes de direção e istrução conferidos ao juiz)" 53 .

Repelem tais diretrizes qualquer cerceamento, que consideram indigno, à autoridade judicial, que deve aparecer como "um juiz-rei, independente, tal como o quer o nacional socialismo" ${ }^{4}$. Como conseqüência, o instituto do ônus da prova, ficando na iniciativa das partes, se esboroa para surgir, em seu lugar, o da "investigação da verdade", no qual, muito embora aquelas não percam o seu poder de iniciativa, é ao juiz "dada a possibilidade de esclarecer oficialmente a realidade dos fatos, utilizando-se de todos os elementos de prova disponíveis" 55 .

Diz ainda, textualmente, Moacyr Amaral Santos: "O legislador brasileiro, para se tornar coerente com as diretrizes políticas traçadas pela Carta de 1937, precisando a ela adaptar o processo, não podia senão acomodá-lo ao sistema autoritário, vigente na Hungria, na Áustria, aprovado pelos juristas alemães e pelos discípulos de Chiovenda, na Itália. Razões de ordem política impunham essa conseqüência" 56 .

O próprio titular da pasta da Justiça, por ocasião da elaboração e promulgação do Código de Processo Civil brasileiro de 1939, declara: "A escolha do sistema foi com efeito uma opção de ordem política do país, isto é, em última análise, do Chefe do Governo. Essa opção ficou irrefutavelmente definida na primeira lei nacional de processo civil decretada pelo Estado Novo - a lei que regulou a cobrança judicial da dívida ativa da Fazenda Pública, ou lei do executivo fiscal. O Estado preferiu, assim, esse sistema, fundado na concentração e na oralidade do processo, para fazer valer em juízo os seus direitos; é natural que aos particulares seja dado o mesmo instrumentos processual. Digo mais. Essa opção era uma conseqüência do regime instaurado em 10 de novembro e definido na Constituição. O Código de Processo Civil exprimirá, no campo em geral tão im- 
permeável do sistema legal, essa tendência vital do regime, entregando ao povo um instrumento fácil, o direito para fazer valer os direitos que a lei civil lhe atribui" ${ }^{57}$. ... "Responsável pelos bens públicos, o Estado não poderá deixar de responder pelo maior deles, que é precisamente a Justiça. Na sua organização e no seu processo, não poderia deixar de imprimir os traços da sua autoridade" 58 .

E esclarece: "Prevaleceu-se o Código, nesse ponto, dos benefícios que trouxe ao moderno direito processual a chamada concepção publicística do processo. Foi o mérito dessa doutrina, a propósito da qual deve ser lembrado o nome de Giuseppe Chiovenda, o ter destacado com nitidez a finalidade do processo, que é a atuação da vontade da lei num caso determinado. Tal concepção nos dá, a um tempo, não só o caráter público do direito processual, como a verdadeira perspectiva sob que devemos considerar a cena judiciária, em que avulta a figura do julgador. $\mathrm{O}$ juiz é o Estado administrando a justiça; não é um registro passivo e mecânico de fatos, em relação aos quais não o anima nenhum interesse, de natureza vital. Não lhe pode ser indiferente o interesse da justiça. Este é o interesse da comunidade, do povo, do Estado, e é no juiz que um tal interesse se representa e personifica" ${ }^{59}$.

\section{O PRINCÍPIO DISPOSITIVO NO CÓDIGO DE PROCESSO CIVIL BRASILEIRO DE 1973}

Ninguém mais autorizado para dizer do Código de Processo Civil Brasileiro de 1973 do que o então Ministro da Justiça Prof. Alfredo Buzaid, sob cujos auspícios o mesmo foi elaborado e promulgado: "O projeto consagra o princípio dispositivo (art. 266), mas reforça a autoridade do Poder Judiciário, armando-o de poderes para prevenir ou reprimir qualquer ato atentatório à dignidade da justiça (art. 130, III)" 60 .

Após especificar o que o projeto considerou atentatório à dignidade da justiça, ressaltando também a modificação substancial no procedimento constante do título VII, Capítulo IV e V do Projeto, ressalta Alfredo Buzaid as modificações quanto à doutrina da provas: "A doutrina das provas sofreu importantes modificações. O artigo 336 declara que "todos os meios legais, bem como os moralmente legítimos, ainda que não especificados neste Código, serão hábeis para provar a verdade dos fatos, em que se fundam a ação ou a defesa". Mas não é só. Permite 
o projeto que o juiz, em falta de normas jurídicas particulares, aplique as regras da experiência comum, subministradas pela observação do que ordinariamente acontece (artigo 339) ${ }^{61}$.

Em uma de suas aulas ${ }^{62}$, explicou-nos o Prof. Alfredo Buzaid: "Ao encerrarmos esta aula, desejo lembrar que o Processo Civil, adotando aquele temperamento entre os dois princípios - o dispositivo e o inquisitório - ampliou os poderes do juiz e fê-lo com a consciência de que era necessário armar o Poder Judiciário de melhores meios para o descobrimento da verdade, sem sacrificar os princípios básicos que estruturam o processo dispositivo".

\section{EPÍLOGO}

Até que ponto deve o juiz, no processo civil, tomar a iniciativa das provas? Mais: deve o interesse público suplantar o interesse privado?

A verdade é que, em processo civil, interesse privado e interesse público de maneira alguma estão em oposição, mas em situação de colaboração, que pode apresentar diversas intensidades e matizes ${ }^{63}$.

Pondera Isidoro Eisner: "Compartimos la opiniõn de que el interés social del proceso no precede ni es superior al interés privado que llevó a su promoción. El interés de la coletividad y del Estado, respecto del proceso, no es de mayor jerarquía que la suma de los intereses individuales tutelados. Ambos se hallan en un mismo grado de valor. La transcendencia social del proceso está más que nada impresa por el hecho de que este es el instrumento capaz de asegurar la continuidad y vigencia del derecho, su afianzamiento y su progreso mediante su exposición diaria a los rigores del medio social que está destinado a satisfacer" 64 .

É oportuno observar com Carlo Furno ${ }^{65}$ que o processo civil faz efetiva a tutela de um interesse público geral, sem que, em geral, este interesse tome partido diretamente no pleito.

Referindo-se ao interesse do Estado no processo civil, Furno desenvolve o seguinte raciocínio: ao lado da finalidade de reintegrar a ordem jurídica, conseguida por meio da condenação de Caio, ao Estado pouco importa que Tício receba 100 à custa de Caio. E, por sua vez, menos ainda importa a Tício que a ordem jurídica fique reintegrada mediante a sentença que con- 
dene a Caio pagar-lhe 100 e se haja obtido a finalidade de pacificação jurídica, com a realização de sua finalidade pessoal, que era a de receber de Caio os 100 que lhe devia.

Ora, tudo bem considerado, torna difícil a apreciação de qual seja o interesse estatal que o processo civil está destinado a tutelar, frente aos interesses privados em conflito. Bem ponderado, o que em definitivo interessa ao Estado é que o conflito de interesses privados que lesa ou põe em perigo a integridade da ordem jurídica seja resolvido e eliminado.

Pouco importa, em resumo, - diz Carlos Furno ${ }^{66}$ - que as partes litigantes o resolvam de comum acordo, licitamente, sem o ministério do juiz letrado, ou que manifestem considerá-lo como solucionado, evitando, afinal de contas, o juízo, ou que, ao invés seja o juiz quem consiga sua solução decidindo o fundo da questão com sentença definitiva.

Nada nos induz a pensar e muito menos a legitimar um egoísmo ilimitado por parte do Estado - adverte, mais adiante, o mesmo autor ${ }^{67}$.

A proibição de fazer justiça pelas próprias mãos - diz ele - não pode ser interpretada no sentido de autorizar a monstruosa invasão pelo poder público da zona privada das relações substanciais ${ }^{68}$.

É evidente que, diante de um possível conluio das partes, realizado com o intuito de violar a lei, como diz Giuseppe Maroni, seria absurdo vincular o juiz ao que elas combinaram ou ao que constitui objeto de provas escritas não contestadas: em tais casos, nenhum meio de indagação deve ser excluído, e a liberdade de convicção dos juízes não pode sofrer limitações, devendo então dominar o princípio inquisitório ${ }^{69}$.

Todavia, segundo outras posições doutrinárias bem lembradas por Raymond Legeais, o juiz deve ter largas possibilidades de controle sobre a regularidade das provas requeridas e fornecidas pelas partes, porém este poder é um poder de direção e deve limitar-se ao bom andamento do processo, não permitinde ao magistrado substituir-se à iniciativa das partes, principalmente em matéria de provas: "Toutefois beaucoup semblent penser que ce pouvoir de direction doit se limiter à la bonne marche de l'instance, que, notament en matière de preuve, il ne saurait permettre au magistrat de se substituer à l'iniciative des particuliers: le rôle du juge serait seulement de hâter la production des preuves" 70 . 
Neste passo, parece-nos merecer especial atenção João de Castro Mendes, ao afirmar ${ }^{71}$ que só se justifica a atribuição de poderes de um órgão do Estado na medida em que se considere que está em jogo no processo um interesse público.

Assim, há que se questionar, a nosso ver, em que medida, no processo civil, o interesse público realmente está em jogo.

Embora a processualística moderna venha mostrando-se em geral favorável ao fenômeno da publicização, propensa até, ao que parece, a aceitar como irreversível a atual concepção publicística do processo, não nos parece que deva desconsiderar-se toda uma experiência histórica anterior.

Sem qualquer vínculo estatal, o juiz romano, durante todo o período clássico, atuava essencialmente à base de um contrato das partes. Simples cidadão do povo, livremente escolhido pelas próprias partes, julgava a demanda na qualidade de árbitro, sem qualquer caráter inquisitorial. Contudo, desfrutava de poderes incomensuráveis: sua sentença era irrecorrível, pelo simples fato de que as partes, plenamente livres em elegê-lo, assumiam o compromisso de acatá-la como definitiva.

Por sua vez, o magistrado, a quem incumbia determinar previamente os princípios da instrução e julgamento das causas e garantir-lhes a execução, gozava do maior prestígio e autoridade, eleito que era, também ele, como os demais magistrados, direta e imediatamente por todo 0 povo ${ }^{72}$, considerado assim com delegação plena do poder soberano do povo. Não estando subordinado hierarquicamente, a não ser ao próprio povo, nem fazia sentido a existência de qualquer recurso a uma instância superior, embora, em matéria criminal, o cidadão condenado tivesse o direito de apelar ao povo reunido no comício (provocatio ad populum).

Desta forma, a política subordinava-se ao direito, e o único da justiça e a eqüidade eram a constante e suprema aspiração, acima de qualquer outra finalidade; o jurisconsulto, ainda quando de sua elevada posição de senador, "magister" ou "quaestor", era sempre "iurisprudens", servindo ao direito e ao povo ${ }^{73}$.

A característica mais saliente da organização judiciária ro. mana, tanto em matéria civil como criminal, era a divisão das funções judiciárias entre o Magistrado, que determinava "a priori" as conseqüências jurídicas dos fatos alegados, quer pelo demandante, quer pelo demandado (ius dicere), e o Juiz, que verificava estas alegações, aplicava-Ihes os princípios indicados pre- 
viamente pelo magistrado, dando fim ao litígio por uma sentença definitiva (iudicare) ${ }^{74}$.

Esta intervenção ativa dos cidadãos nos julgamentos dos processos dava à justiça um caráter eminentemente popular e liberal, no dizer de Bonjean ${ }^{75}$, além de se notabilizar por sua ddmirável rapidez e eficiência. Efetivamente, a decisão, do ponto de vista estritamente jurídico - observa ele - exige conhecimentos técnicos, que somente podem ter pessoas afeitas a um estudo especial da jurisprudência, ao passo que o julgamento do fato supõe apenas um espírito justo e reto, porém exige muito tempo. Sob este duplo aspecto, não há dúvida de que os romanos encontraram a mais satisfatória combinação: os magistrados, que só se ocupavam dos processos para lhes determinar os princípios pelos quais as questões seriam instruídas e julgadas, podiam despachar grande quantidade de processos; quanto às verificações de fato, sendo grande o número de jurados aos quais podiam ser distribuídas as causas, chegando, ao tempo de Augusto, a ser inscritos mil jurados nas listas anuais ${ }^{76}$, cada um deles, ocupando-se de poucos processos, podia dedicar-se todo o tempo necessário ao seu exame.

Assim sendo, por mais que as relações jurídicas da época fossem complexas, a ponto de se fazer necessário criar o pretor peregrino, além do pretor urbano, a administração da justiça era extremamente ágil e eqüânime.

Eis a razão do veemente apelo de Garcia Garrido: "La intrincada selva de disposiciones legales, que constituye hoy el Derecho positivo, solo puede superarse volviendo a los cauces de una verdadera Jurisprudencia, dominada como en el mundo romano por la utilidad, la equidad y la justicia. En este sentido, se impone un retorno a los juristas romanos; la Jurisprudencia romana es, en efecto, una auténtica escuela de liberdad y nos muestra el proceder perfecto del Derecho" 77 .

Nas modestas limitações do presente trabalho, sem discutirmos até que ponto o atual sistema publicista realmente confere ou não poderes e autoridade ao juiz, ou em que medida o processo, hoje, minuciosamente regulado, efetivamente atende aos interesses comuns da sociedade, comparando-se ao regime da "ordo iudiciorum privatorum" dos romanos, inquestionavelmente não podemos deixar de reconhecer que, em matéria de processo e organização judiciária, o período clássico romano é ainda a grande fonte de ensinamentos para os nossos dias. 


\section{NOTAS}

1) Vide João de Castro Mendes, DO CONCEITO DE PROVA EM PROCESSO CIVIL, Dissertação de Doutoramento em Ciências Jurídicas na Faculdade de Direito da Universidade de Lisboa, Edições Ática, 1961, p. 122 e s.

2) Washington de Barros Monteiro. CURSO DE DIREITO CIVIL, Parte Geral, 15. ${ }^{\mathrm{a}}$ edição, Saraiva, 1977, p. 11.

3) Alberto Moniz da Rocha Barros, O PODER ECONÔMICO DO ESTADO CONTEMPORÂNEO E SEUS REFLEXOS NO DIREITO, Monografia para concurso à cadeira de Introdução à Ciência da Faculdade de Direito da USP, Empresa Gráfica da Revista dos Tribunais Ltda., 1953, p. 229.

4) Ob. cit., p. 241.

5) Emilio Costa, PROFILO STORICO DEL PROCESSO CIVILE ROMANO, Athenaeum, Roma, MCMXVIII, p. 143.

6) Sílvio Meira, PROCESSO CIVIL ROMANO. Gráfica Falangola Editora, Ltda., 2. ${ }^{\text {a }}$ ed. p. 31 ; Emilio Costa, ob. cit. p. 72,

7) Ob. cit. p. 74.

8) Gai. 4, 105.

9) Cf. A. Giffard, LA PROCÉDURE ROMAINE, p. 120.

10) D. $15,1,3,11$.

11) Alejandrino Fernandes Barreiro, PRESUPUESTOS DE UNA CONCEPCIÓN JURISPRUDENCIAL DEL DERECHO ROMANO, Universidad de Santiago de Compostela. 1976, p. 23.

Cf. Xavier D'Ors, POSICIONES PROGRAMATICAS PARA EL ESTUDIO DEL DERECHO ROMANO, Santiago de Compostela, 1979 , p. 47 e s.

12) Alejandrino Fernandes Barreiro, ob. cit. p. 27.

13) Ob. cit. p. 32.

14) Carlos Lessona, TEORIA GENERAL DE LA PRUEBA EN DERECHO CIVIL, trad. por Enrique Aguilera de Paz, Madrid, Editorial Reus, 1928, vol. I, p. 500.

15) Ações interrogatórias são as que se concedem ao demandante depois de ter sido interrogado o demandado, na presença do magistrado - interrogatio in iure - e cujo texto e fórmula se redigem de conformidade com o depoimento, a cujo teor será necessário ater-se subsequentemente, por ter para o interrogado valor vinculante (D. $11,1,1,1)$.

16) Cf. Vicenzo Arangio-Ruiz, INSTITUCIONES DE DERECHO ROMANO trad. José M. Caramés Ferro, Edit. Delpalma, Buenos Aires, 1952, p. 126.

17) Ob. cit. p. 164.

18) C. 4, 20,1 (Reconstituição das Basílicas, por Cujácio): "Contra scriptum testimonium, non scriptum testimonium non fertur".

19) C. 4, 20, 9, 20 (Imp. Constantinus ad Julianum Praesidem): "Simili modo sanximus, ut unius testemonium nemo iudicum in quacunque causa facile patiatur admitti. Et nune manifeste sancimus, ut unius omnino testis responsio non audiatur, etiamsi praeclarae Curiae honore praefulgeat".

20) Nov. 90, 1: “... Et non quosdam artifices ignobiles, neque vilissimos, neque nimis obscuros ad testimonium procedere".

21) Cod. 1, 5, 21: "Sancimus, contra ortodoxos quidem litigantes nemini haeretico vel his etiam, qui iudaicam superstitionem colunt, esse in testimonia communionem".

22) C. 4, 20, 16: "Si conventus quis negaverit ... aut alii quidem testes pro veritate deponentes tunc ipsae praeter poenam vigintiquatuor aureorum non possit habere licentiam obiiciendae exceptionis pecuniae non numeratae". 
23) C. 4, 20, 9 (cit.): "Iusiurandi religione testes priusquam perhibeant testimonium, iam dudum arctari praecepimus".

24) Nov. 90, 1: "Si vero ignoti quidam fuerint undiques et aliquid apparuerit circa testimonii veritatem corrumpere festinantes: posse eos etiam verberibus subiacere".

25) Nov. 90, 1 (cit): "Et iudices, si quidem administratores fuerint, hoc ipsi agant".

26) Nov. 112, 3: "Cum autem omnium causarum finem celeriter procedere velimus, illorun quoque fraudibus adversamur, qui tantummodo actiones proponunt nec tamen eas usque ad finem litis persequi volunt, dicentes legem esse quae caveat ne quis actiones suas exercere invitus cogatur. Hanc igitur fraudem cum exstinguere studeamus iubemus memoratas legis auxilio non uti eos qui actiones suas contra aliquem proponunt, sive per conventionem iudicialem sive per preces imperatori oblates et iudici insinuatas atque per eum in notitiam adversarii perlatas et a iudice legitime examinari coeptas.

Legis autem privilegio quae necessitatem non imponit invitis praedictos modos adversus adversarios movent".

27) C. 3, 7, 1: "Invitus agere vel accusare nemo cogatur".

28) Ugo Ziletti, STUDI SUL PROCESSO CIVILE GIUSTINIANEO, Milano, Dott: A. Giufrè, Edit. 1965, p. 100.

Para uma visão mais ampla do tema, no direito justinianeu, confrontem-se ainda os seguintes textos: C. 7, 39, 8, 3; C. 7, 63,5 ; C. $3,1,13$; Nov. 49 , pr.; Nov. 53,1 ; Nov. 126 ; Nov. 73 ; Nov. 82 ; Nov. 86 ; Nov. 90 ; Nov. 93 ; Nov. 96 ; Nov. $113 ; 115$; Nov. 125 e Nov. 124.

29) Moacy Lobo da Costa, O AGRAVO NO DIREITO LUSITANO, Borsoi, Rio, 1974, p. 15.

30) FUERO JUZGO EN LATIN Y CASTELLANO, Real Academia Espar̃ola, Madrid, Ibarra Impresor de Cámara de S. M. 1815, p. 26.

31) Moacy Lobo da Costa, ob. cit. p. 23.

32) Jácome Ruiz, FLORES DE LÁS LEYES, versão de Manuel Paulo Merêa, Coimbra, Imprensa da Universidade 1918, p. 35.

33) Guilherme Braga da Cruz, O DIREITO SUBSIDIÁRIO NA HISTÓRIA DO DIREITO PORTUGUÊS, Coimbra, 1975, p. 201/202.

34) SIETE PARTIDAS, 3, 12, pr.

35) Id. 3, 12, 2 .

36) Ord. Af., 3, 32, pr.

37) Ord. Man., 3, 50, pr. 1.

38) Ord. Filip., 3, 66.

39) Moacyr Amaral Santos, PROVA JUDICIÁRIA NO CíVEL E COMERCIAL, Vol. 1, 2. ${ }^{\mathrm{a}}$ ed., 1952, p. 109.

40) Vejam-se os seguintes textos: Ord. Filip., 3, 52, pr. 1, 2; 3, 88,$16 ; 3,20,4 ; 3,33$, pr., assim como o Reg. 737, artigos 169, $172,173,191,209,214$ e 230.

41) Moacyr Amaral Santos ob. cit., p. 109.

42) Gabriel de Rezende Filho, SOCIALIZAÇÃO DI DIREITO, Oração de paraninfo dos diplomados da Faculdade de Direito de São Paulo, 1941, p. 15.

43) Georges Ripert, O REGIME DEMOCRÁTICO E O DIREITO CIVIL MODERNO, apud Cunha Barreto, ORALIDADE E CONCEITUAÇÃO NO PROCESSO CIVIL, Rev. Forense, 7/195.

44) Gabriel de Rezende Filho ob. cit., p. 290.

45) Ob. cit. p. 110.

46) id.

47) Giuseppe Chivenda, LA RIFORMA DEL PROCEDIMENTO CIVILE E PROPOSTA DALLA COMISSIONE PER IL DOPO GUERRA - relazione e testo annotato per cura de G. C.", agosto/ 
1920, § 47, p. 31, apud Alberto Moniz da Rocha Barros, ob. cit. p. 242 .

48) Antonio Segni e Sergio Costa, "Procedimento Civile, in NOVISSIMO DIGESTO ITALIANO, XIII, p. 1029.

49) Moacyr Amaral Santos, ob. cit. p. 112.

50) José Monteiro de Castro "O Sistema Oral e a Realidade Brasileira”, in REVISTA FORENSE, 78/434.

51) Bernhardt, "O Domínio das Partes no Processo Civil", in REVISTA FORENSE, 78/468.

52) Id. REV. FORENSE, 78/256.

53) Giuseppe Maranini, "Princípio Dispositivo e Princípio Inquisitório" in REV. FORENSE, 78, 260.

54) Moacyr Amaral Santos, ob .cit. p. 114; Bernhardt, ob. cit. id.

55) Id. p. 118.

56) Id.

57) Francisco Campos, "A Reforma do Processo Civil", in REV. FORENSE, 78/189.

58) Francisco Campos, EXPOSIÇÃO DE MOTIVOS AO CÓDIGO DE PROCESSO CIVIL.

59) Id.

60) Alfredo Buzaid, EXPOSIÇÃO DE MOTIVOS AO CóDIGO DE PROCESSO CIVIL, Brasília, 1972.

61) Id.

62) Prof.Alfredo Buzaid, Aula proferida no Curso de Pós-Graduação da Faculdade de Direito da USP, em 15.05.1978 (de nossas anotações taquigráficas) .

63) Gian Antonio Micheli, LA CARGA DE LA PRUEBA trad. Santiago Sentís Melendo, Buenos Aires, EJEA, 1961, p. 93.

64) Isidoro Eisner, LA INMEDIACIÓN EN EL PROCESO, Ed. Delpalma, Buenos Aires, 1963, p. 13.

65) Carlo Furno, TEORIA DE LA PRUEBA LEGAL, Ed. Revista de Derecho Privado, Madrid, 1954, p. 44.

66) Ob. cit. p. 153.

67) Ob. cit. p. 153

68) Ob. cit. p. 158.

69) Giuseppe Maroni, ob. cit., p. 173.

70) Raymond Legeais, LES REGLES DE PREUVE EN DROIT CIVII, Paris, 1955, p. 192.

71) Ob. cit. p. 123.

72) L. B. Bonjean, TRAITÉ DES ACTIONS CHEZ LES ROMAINS, Paris 1845, I Tomo, p. 36.

73) Manuel Jesus García Garrido, CASUISMO Y JURISPRUDENCIA ROMANA, Madrid, 1973, p. 39.

74) L. B. Bonjean, ob. cit. p. 38.

75) Id., p. 39.

76) Id., p. 45.

77) Manuel Jesus García Garrido, ob. cit., p. 9. 